\title{
Circadian variation of fatigue in paralytic poliomyelitis and postpolio syndrome: just fatigue or masked restless legs syndrome?
}

Variação circadiana da fadiga na poliomielite e na síndrome pós-polio: apenas fadiga ou síndrome das pernas inquietas?

\section{Dear Editors}

We read with interest the manuscript published by Viana et al. ${ }^{1}$. These authors observed in a small cohort of paralytic poliomyelitis (PP) and postpolio syndrome (PPS) patients a significant circadian fatigue in both forms. The authors also evaluated polysomnographic variables lacking correlations between PSG data and fatigue. In PP, an acute disease resulting in flaccid paralysis, it has been shown that polio virus may induce apoptosis and consequently CNS injury, which leads to paralysis. Therefore during its clinical course an increasing and progressive fatigue may represent an integral part of motor symptoms, while PPS circadian impairment of fatigue may be more puzzling. Sleep disorders and particularly sleep related breathing disorders, restless legs syndrome and periodic limbs movement of sleep (PLMS) were described in PPS ${ }^{2,3}$. Small cohorts, single case reports, uncontrolled design, selected samples complaining of fatigue, sleepiness are critical issues for these reports. An intriguing model and a probable unifying hypothesis may be represented by restless legs syndrome (RLS). A circadian fatigue in PPS may be the expression of unrecognized RLS in PPS. The frequency of RLS and PLMS is higher than general population in several neurological diseases ${ }^{4.5}$. The $95 \%$ of highly associated RLS conditions are linked with inflammatory/immune changes. This observation suggested that RLS is mediated or affected by inflammation as recently demonstrated by elevated C-reactive protein (CRP) in RLS with severe PLMS ${ }^{4}$. Similarly in PPS it is still debated whether the denervation processes are caused by further loss of motor neurons due to normal aging or active disease processes, involving chronic inflammatory damage ${ }^{6}$. These observations are supported by the increased expression of pro-inflammatory cytokines in PPS ${ }^{6}$. The driver of these inflammatory mechanisms is still unclear. Therefore RLS and PPS may share a common pro-inflammatory condition. Viana et al..$^{1}$ found more than one third of PPS patients had PLMS, although no statistical correlation was found between fatigue and PSG. In addition, as correctly stated in discussion, authors ${ }^{1}$ did not evaluate RLS in their PPS patients.

Although small PPS samples with RLS and/or PLMS do not allow any generalization, the common inflammatory pathways and also a natural propensity to circadian trend of fatigue in PPS, as interestingly demonstrated by Viana et al. ${ }^{1}$, may support the association of PPS with RLS. Epidemiological studies with controlled design are needed to explore the real magnitude of RLS in PPS and to evaluate possible common mechanisms involved in the development of RLS.

Andrea Romigi ${ }^{1,2}$, Fabio Placidi ${ }^{1}$, Elisa Evangelista ${ }^{1}$, Maria T. Desiato ${ }^{3}$

\section{References:}

1. Viana CF, Pradella-Hallinan M, Quadros AA, Marin LF, Oliveira AS. Circadian variation of fatigue in both patients with paralytic poliomyelitis and post-polio syndrome. Arq Neuropsiquiatr 2013;71:442-445.

2. Araujo MA, Silva TM, Moreira GA, Pradella-Hallinan M, Tufik S, Oliveira AS. Sleep disorders frequency in post-polio syndrome patients caused by periodic limb movements. Arq Neuropsiquiatr 2010;68:35-38.

3. Marin LF, Carvalho LB, Prado LB, Quadros AA, Oliveira AS, Prado GF. Restlesslegs syndrome in post-polio syndrome: a series of 10 patients with demographic,clinical and laboratorial findings. Parkinsonism Relat Disord 2011;17:563-564.

\footnotetext{
'Sleep \& Epilepsy Center, University of Rome "Tor Vergata", General Hospital, Rome, Italy;

${ }^{2}$ IRCCS NEUROMED Via Atinense 18 Pozzilli (IS), Italy;

${ }^{3}$ Neurophysiopathology, Unit San Eugenio Hospital, Rome, Italy.

Correspondence: Andrea Romigi; University of Rome Tor Vergata, System Medicine, General Hospital Sleep \& Epilepsy Center; Viale Oxford, 81; Rome 00133, Italy; E-mail: a_romigi@inwind.it

Conflict of interest: There is no conflict of interest to declare.

Received 01 September 2013; Received in final form 09 January 2014; Accepted 29 January 2014.
} 
Weinstock LB, Walters AS, Paueksakon P. Restless legs syndrometheoretical roles of inflammatory and immune mechanisms. Sleep Med Rev 2012;16:341-354.

5. Romigi A, Albanese M, Liguori C, Placidi F, Marciani MG and Massa R. Sleep-Wake Cycle and daytime sleepiness in the myotonic dystrophies. J Neurodegenerat Dis 2013, doi.org/10.1155/2013/692026

6. Fordyce CB, Gagne D, Jalili F, et al. Elevated serum inflammatory markers in post-poliomyelitis syndrome. J Neurol Sci 2008;271:80-86. 